\title{
23. A thirst for power: A global analysis of water consumption for energy production
}

\author{
Edward Spang \\ University of California, Davis, United States
}

\begin{abstract}
Water and energy resource systems are fundamentally interrelated. Secure and reliable access to both resources is critical to basic survival, as well as ongoing economic development at all scales and in every region of the world. At the most basic level, water is required in the production of energy, and energy is required in the treatment and transport of water - a linked relationship known as the water-energy nexus. While both sides of the water-energy nexus merit attention for improving resource use, this research effort focuses on the water requirements of energy systems and the associated implications for national water security.
\end{abstract}

As competition for finite freshwater resources intensifies around the world, it is increasingly important to balance the demand for water across multiple sectors while also protecting ecosystems (Palaniappan et al. 2008). Understanding the water demand of energy systems is fundamental to overall national water security, since the production of energy requires significant quantities of freshwater. While agricultural demand dominates overall demand for water in many regions of the world (United Nations Educational, Scientific and Cultural Organisation (UNESCO) 2003), the demand for water from the energy sector can be a major competitor. In the United States it is a relatively even split between water withdrawals for irrigating crops (40 per cent of total) and for cooling thermoelectric power plants (39 per cent) (Department of Energy (DOE) 2006). Further, the division between agricultural and energy-based demand for water is no longer straightforward as irrigated crops are increasingly being converted to biofuels in many regions (Gerbens-Leenes et al. 2009).

The quantity of water consumed by the energy sector varies substantially by the technology deployed for fuel extraction and processing (fossil fuels, nuclear fuels and biofuels) as well as electricity production (thermoelectric and renewable technologies). As a regional portfolio of energy production technologies changes or expands, there is an associated fluctuation in the burden on local water resources. Figure 1 represents a consolidation from the 
literature of water consumption estimates for a variety of energy technologies (note that the estimates are provided in log scale to show variability within and across technology categories).

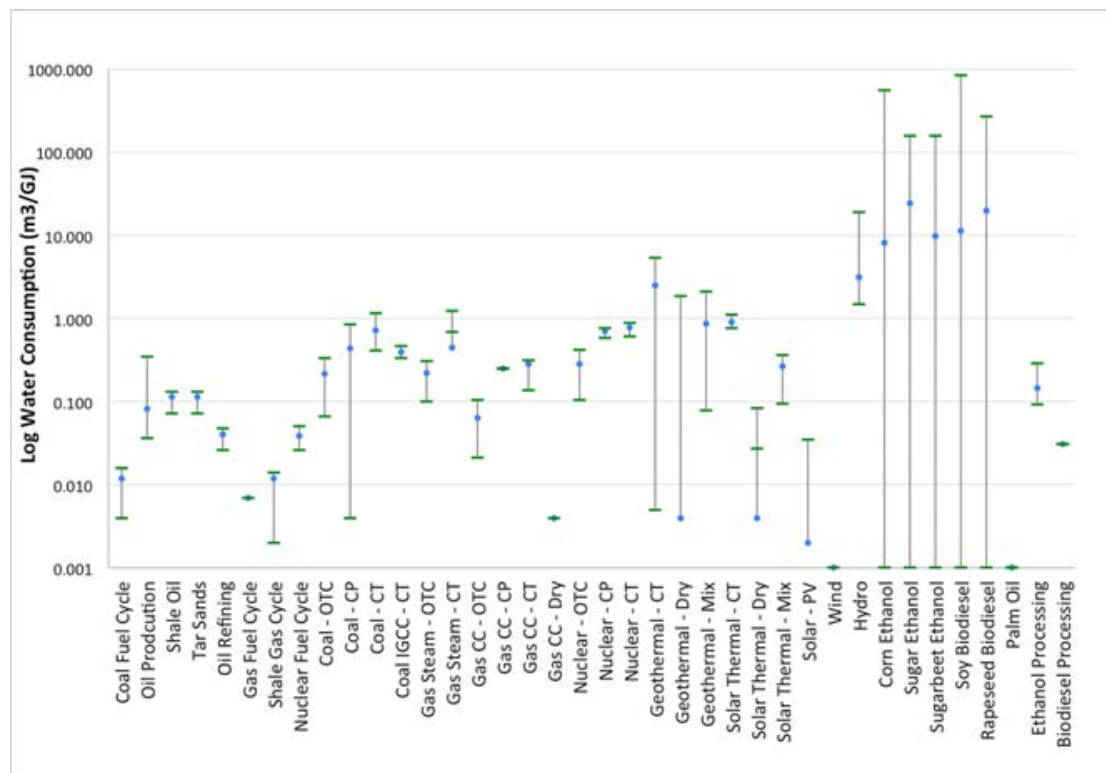

Figure 1: Water consumption coefficients for energy technologies (log scale)

Source: Gleick 1994; Fthenakis and Kim 2010; Mekonnen and Hoekstra 2010; Mielke et al. 2010; Macknick et al. 2011; Wu et al. 2009; National Renewable Energy Laboratory (NREL) 2010; Mittal 2010.

Given the potential impacts of energy policy decisions on regional water security, the application of metrics to assess the water burden of national energy portfolios is underdeveloped. Most of the literature has focused on estimating: the water consumption of specific energy technologies (see sources listed for Figure 1); country-level or regional analyses of water consumption across a complete energy portfolio (DOE 2006; Elcock 2010); or, a global analysis of water consumption by a single energy type (Vassolo and Döll 2010). A clear estimation of water consumption for complete national energy portfolios at the global scale does not, however, currently exist.

This research addresses this knowledge gap by synthesising and expanding previous work to develop a global distribution of water consumption by national-level energy portfolios. The water consumption for energy production (WCEP) indicator was defined and calculated to quantify the relative water use of 158 national energy systems. WCEP is an estimation of freshwater consumption across all energy categories, including fossil fuels, nuclear fuels, biofuels and electricity production. Hydroelectricity is not included in the analysis because 
its associated water consumption (often defined as the estimated evaporation from the reservoir) is only partially linked to energy consumption. The majority of dams serve multiple purposes, including the essential water security services of flood control and water storage (Briscoe 2009). An overview of the global results of the WCEP assessment is provided in map form in Figure 2.

Research results estimate global WCEP at approximately 45 billion cubic metres of water per year. Of course, there is high variability in the WCEP across the 158 countries that were assessed (ranging from nearly zero to 12.6 billion cubic meters). As expected, larger countries with greater economic activity had the highest WCEP values. In terms of the per capita estimates for WCEP, the countries that were heavy producers of fossil fuel or biofuels demonstrated greater intensity of energy-based water consumption (see Figure 3). These results suggest that the economic imperative to develop fossil fuels drives higher WCEP, even in countries that lack sufficient water supplies. Meanwhile, biofuels require so much water that any national commitment to their production has significant water consumption implications.

While these results are based on a comprehensive review of currently available data, future research in this area could be significantly enhanced through better data and widespread adoption of consistent reporting mechanisms. Additional opportunities to expand the field include increasing the resolution of the study regions, characterising WCEP trends over time, and exploring innovative policy approaches to managing national WCEP effectively.

This research contributes an improved set of metrics to characterise the baseline conditions of integrated water-energy systems. By benchmarking water consumption for energy to standard measures, policy-makers can better understand and track the status of this coupled system. They are then able to set targets to minimise water consumption, or at least understand some of the water implications of particular energy policy initiatives. Given the critical role that the monitoring of greenhouse gas emissions has played in shaping energy portfolios, it is time to similarly incorporate water consumption implications into energy portfolio planning. 


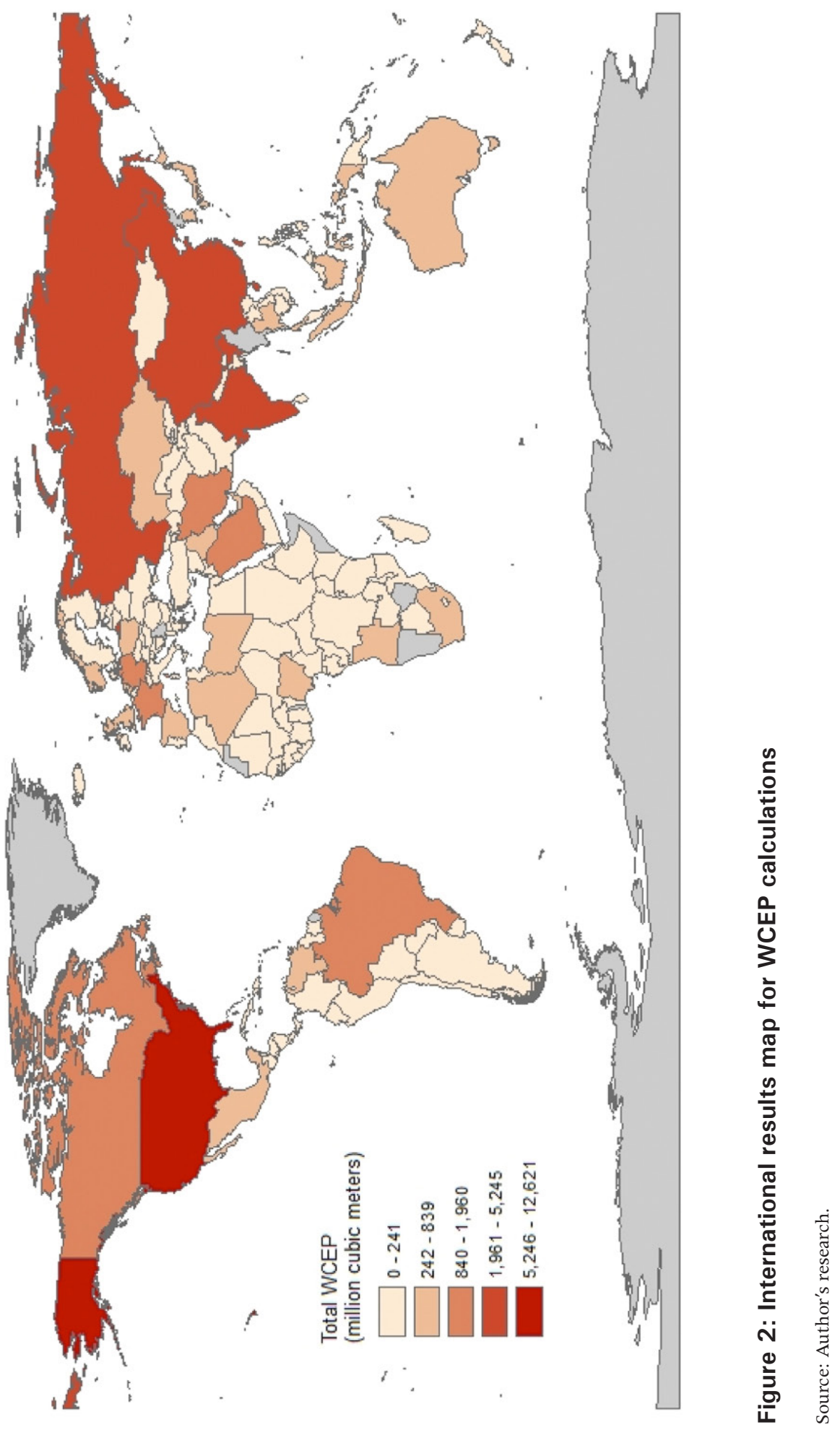



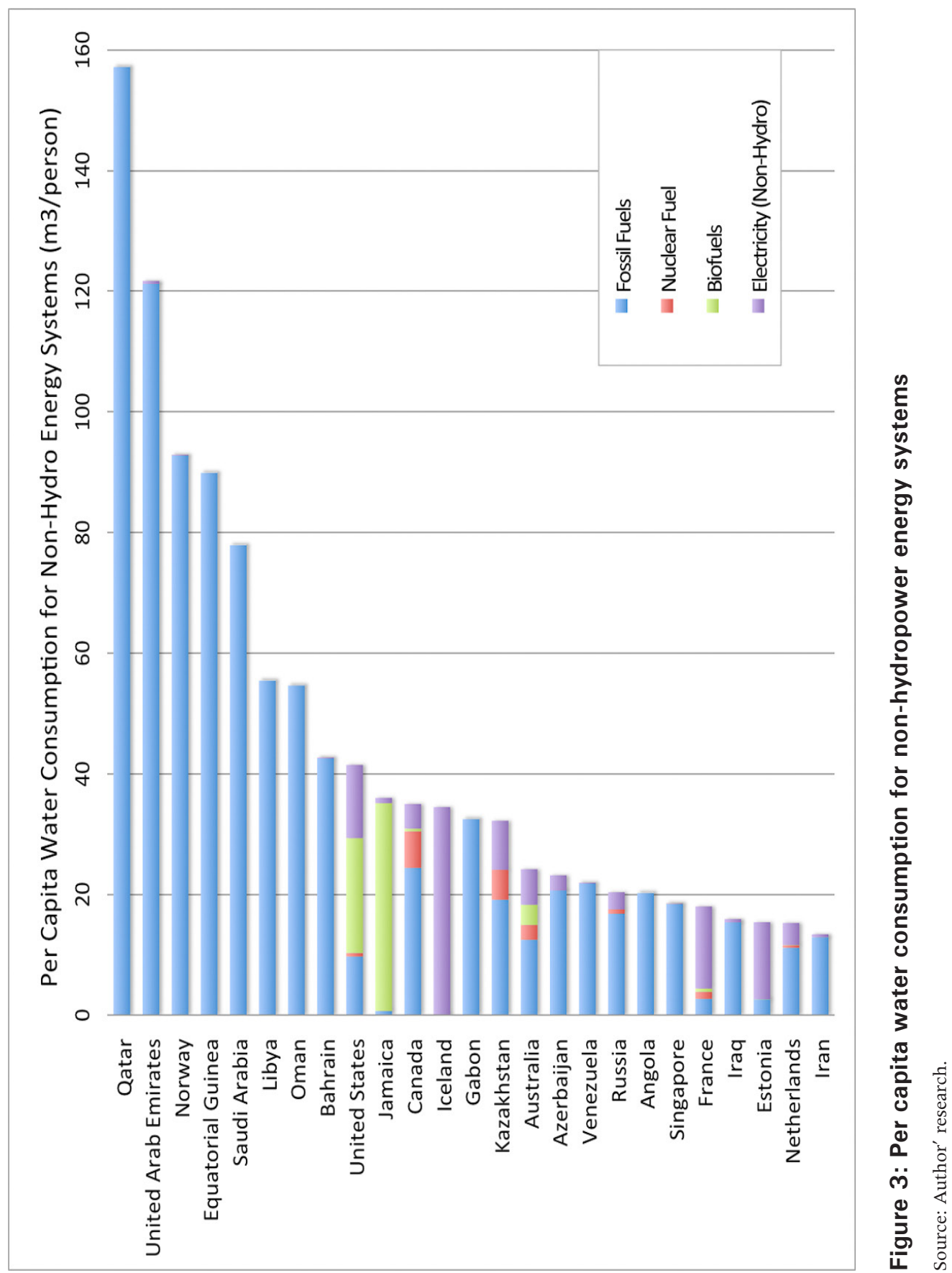
Global Water: Issues and Insights

Dr Edward Spang is the Program Manager for the Center for Water-Energy Efficiency (CWEE) at the University of California, Davis. CWEE is a unique academic centre that seeks to research, develop, and disseminate efficient technologies and system-based policies for the integrated conservation of water and energy resources. His doctoral research focused on the link between water and energy resources at the global level, including the critical importance of improving the efficiency of resource use in both sectors. His previous work included targeted studies and projects within each sector. Spang holds a BA degree from Dartmouth College and an MALD and PhD from the Fletcher School, Tufts University. He can be contacted at esspang@ucdavis.edu.

\section{References}

Briscoe, J., 2009. 'Water security: why it matters and what to do about it', Innovations: Technology, Governance, Globalization 4(3):3-28.

Department of Energy (DOE), 2006. Energy Demands on Water Resources: Report to Congress on the interdependency of energy and water. United States Government, Washington, D.C.

Elcock, D., 2010. 'Future US water consumption: the role of energy production', Journal of the American Water Resources Association 46(3):447-60.

Fthenakis, V. and Kim, H.C., 2010. 'Life-cycle uses of water in US electricity generation', Renewable and Sustainable Energy Reviews 14(7):2039-48.

Gerbens-Leenes, W., Hoekstra, A.Y. and van der Meer, T.H., 2009. 'The water footprint of bioenergy', Proceedings of the National Academy of Sciences 106(25):10219-23.

Gleick, P.H., 1994. 'Water and energy', Annual Reviews in Energy and the Environment 19(1):267-99.

Macknick, J., Newmark, R., Heath, G. and Hallett, K.C., 2011. A Review of Operational Water Consumption and Withdrawal Factors for Electricity Generating Technologies. National Renewable Energy Laboratory (NREL), Golden, Colorado.

Mekonnen, M.M and Hoekstra, A.Y., 2010. The Green, Blue and Grey Water Footprint of Crops and Derived Crop Products, Value of Water Research Report Series. UNESCO, Delft, The Netherlands. 
Mielke, E., Anadon, L. and Narayanamurti, V., 2010. 'Water consumption of energy resource extraction, processing, and conversion', Discussion Paper Series, Harvard Kennedy School, Cambridge, Massachusetts.

Mittal, A., 2010. Energy-Water Nexus: Many uncertainties remain about national and regional effects of increased biofuel production on water resources, Government Accountability Office (GAO), Washington, D.C.

National Renewable Energy Laboratory (NREL), 2010. ‘Energy technology cost and performance'. Available from: http://www.nrel.gov/analysis/ capfactor.html.

Palaniappan, M., and Gleick, P.H., 2008. 'Peak water', in The World's Water, vol. 2009, Island Press, Washington, D.C.

United Nations Educational, Scientific and Cultural Organisation (UNESCO), 2003. Water for People - Water for Life, World Water Development Report, UNESCO, Berghan Books, New York.

Vassolo, S., and Döll, P. 2005. 'Global-scale gridded estimates of thermoelectric power and manufacturing water use', Water Resources Research 41(4):doi: 10.1029/2004WR003360.

Wu, M., Mintz, M., Wang, M. and Arora, S., 2009. Consumptive Water Use in the Production of Ethanol and Petroleum Gasoline, Argonne National Laboratory (ANL), Illinois. 
This text taken from Global Water: Issues and Insights by R. Quentin Grafton, Paul Wyrwoll, Chris White and David Allendes, published May 2014 by ANU Press, The Australian National University, Canberra, Australia. 